\title{
Educational interventions to empower nursing home residents: a systematic literature review
}

This article was published in the following Dove Press journal:

Clinical Interventions in Aging

28 September 2016

Number of times this article has been viewed

\section{Daniela Schoberer' \\ Helena Leino-Kilpi ${ }^{2}$ \\ Helga E Breimaier' \\ Ruud JG Halfens ${ }^{3}$ \\ Christa Lohrmann'}

'Institute of Nursing Science, Medical University of Graz, Graz, Austria;

${ }^{2}$ Turku University Hospital, University of Turku, Turku, Finland; ${ }^{3}$ Department of Health Services Research, School for Public Health and Primary Care (CAPHRI), Maastricht University, Maastricht, the Netherlands
Correspondence: Daniela Schoberer Institute of Nursing Science, Medical University of Graz, Billrothgasse 6, 8010 Graz, Austria

Tel +433163857 2069

Fax +433I63857 2068

Email daniela.schoberer@medunigraz.at
Purpose of the study: Health education is essential to improve health care behavior and self-management. However, educating frail, older nursing home residents about their health is challenging. Focusing on empowerment may be the key to educating nursing home residents effectively. This paper examines educational interventions that can be used to empower nursing home residents.

Methods: A systematic literature search was performed of the databases PubMed, CINAHL, CENTRAL, PsycINFO, and Embase, screening for clinical trials that dealt with resident education and outcomes in terms of their ability to empower residents. An additional, manual search of the reference lists and searches with SIGLE and Google Scholar were conducted to identify gray literature. Two authors independently appraised the quality of the studies found and assigned levels to the evidence reported. The results of the studies were grouped according to their main empowering outcomes and described narratively.

Results: Out of 427 identified articles, ten intervention studies that addressed the research question were identified. The main educational interventions used were group education sessions, motivational and encouragement strategies, goal setting with residents, and the development of plans to meet defined goals. Significant effects on self-efficacy and self-care behavior were reported as a result of the interventions, which included group education and individual counseling based on resident needs and preferences. In addition, self-care behavior was observed to significantly increase in response to function-focused care and reasoning exercises. Perceptions and expectations were not improved by using educational interventions with older nursing home residents.

Conclusion: Individually tailored, interactive, continuously applied, and structured educational strategies, including motivational and encouraging techniques, are promising interventions that can help nursing home residents become more empowered. Empowering strategies used by nurses can support residents in their growth and facilitate their self-determination. Further research on the empowerment of residents using empowerment scales is needed.

Keywords: health education, older people, empowerment, self-efficacy, self-care activities, self-determination

\section{Introduction}

Education is not only important to young people but also a lifelong process. Adult education about several health care topics is essential to improve health care behavior and self-management as well as reduce risky behavior. Such topics include fall prevention, nutrition, and alcohol use. ${ }^{1-3}$ According to the World Health Organization, health education not only means conveying verbal or written information but also means promoting the motivation, skills, and confidence of people so that they take action to improve their health. ${ }^{4}$ One of the health strategies of the European 
Union, which supports this aspect of health education, is the empowerment of people. ${ }^{5}$

In older people, age-related conditions and the related decline in physical and cognitive functions require that they receive appropriate education to continue living as actively and independently as possible. However, health education in older people, especially in frail, older nursing home residents, is challenging. The first challenge is due to the cognitive decline observed in older people due to aging. ${ }^{6}$ According to the results of cognitive psychology research, older people process information more slowly, have less cognitive flexibility (eg, are less willing to alter their judgments), and have lower abilities to think divergently (ie, to generate alternative explanations or solutions). In addition, the working memory capacity and the ability to focus on specific information decline as people age. ${ }^{6}$ The second challenge to educating older people is that many prefer not to be actively involved in treatment, self-care, and decision making. ${ }^{7-9}$ This preference for the passive role may be their way of avoiding taking responsibility for undesirable events or incorrect decisions. ${ }^{10}$ In addition, older people commonly hold the opinion that undesirable events (such as falls) are inevitable and unavoidable. ${ }^{9-11}$ Although many older people perform regular physical activity to stay active and have positive attitudes toward personal health care, some of them and especially frail nursing home residents believe that certain interventions (such as bodily exercise) are not effective due to reduced physical ability. ${ }^{12}$

For these reasons, a great deal of effort must be invested to support the empowerment of older people to increase their benefits from educational interventions. By becoming empowered, people can enjoy their life to the greatest extent possible on the basis of their own choices. ${ }^{13}$ To achieve empowerment, people must obtain knowledge that is related to individual needs and expectations. ${ }^{14,15}$ Gibson defined empowerment as:

... a process of recognizing, promoting and enhancing people's ability to meet their own needs, solve their own problems and mobilize the necessary resources in order to feel in control of their own lives. ${ }^{16}$

Empowerment based-interventions are based on strong guiding principles such as self-determination and autonomy. ${ }^{17}$ By providing empowering care, nurses help increase the residents' independence and their feelings of autonomy. ${ }^{18}$ The nurses cannot give them these feelings but can support the residents during the process of empowerment. ${ }^{15}$ In patient education, therefore, empowerment is both a process and an outcome. During the empowerment process, residents increase their abilities to act autonomously, think critically, and gain an enhanced sense of self-efficacy as a result. ${ }^{19}$ Self-efficacy is a strong predictor of self-care behavior, which influences behavior both directly and indirectly by influencing goal setting, outcome expectations, and perception of facilitators and impediments. ${ }^{20}$

Although the presence of empowerment care is a significant predictor of the quality of life, ${ }^{21}$ empowerment of nursing home residents is seldom discussed in research articles. ${ }^{22}$ However, focusing on empowerment may be the key to educating nursing home residents effectively. To the best of our knowledge, no systematic review is currently available that describes educational interventions used to specifically empower nursing home residents. A recent review was published on person-centered care in aged-care facilities, where a focus was placed on interventions to enhance residents' autonomy, choices, sense of personal control, independence, and interactions, but staff training, organizational changes, and the creation of a positive atmosphere were primary goals rather than resident education. ${ }^{23}$

Therefore, the aim of this research was to identify educational interventions that could be used to empower nursing home residents. The following research questions are asked: which educational interventions are used in intervention studies to empower nursing home residents and how effectively do educational interventions empower nursing home residents?

\section{Methods}

To answer the research questions, a systematic literature search was performed. The PubMed, CINAHL, CENTRAL, PsycINFO, and Embase databases were screened to select articles that had been published during this century (from January 1, 2000 to April 1, 2016), selecting current studies that had been written in English or German. The search was limited to clinical trials (eg, clinical trials, controlled clinical trials, and randomized clinical trials) in order to target intervention studies. Search terms (shown in Table 1) were used with truncations and the Boolean operators OR (horizontal terms) and AND (vertical combinations). The outcome

Table I Search terms used in the database searches

\begin{tabular}{ll}
\hline People of interest & Residents, older people, older adults, elderly \\
Intervention & Educate, inform, train, instruct \\
Outcomes & Knowledge, self-efficacy, self-determination, \\
& autonomy, self-care behavior, self-care activity, \\
& self-management, mastery, empower \\
Setting & Nursing home, "Residential Facilities" (MESH) \\
\hline
\end{tabular}


terms were based on outcome measures that focused on empowerment in patient education. ${ }^{14-19}$

In addition, a manual search of reference lists of selected papers and reviews on the topics of empowerment and patient education was performed to identify additional relevant articles. ${ }^{6,23-25}$ To identify gray literature, a search was conducted in the SIGLE and Google Scholar to a page depth of 12, using the keywords empower, self-efficacy, self-determination, autonomy, and resident.

\section{Criteria for considering studies: inclusion and exclusion criteria}

In order to be included, studies had to meet the following criteria:

- Included older people (from 65 years on)

- Addressed residents living in nursing homes or similar long-term institutional settings

- Described any educational intervention that implied that information was provided, and/or motivation, skills, and confidence necessary to take action to improve health were fostered ${ }^{4}$

- Focused on outcomes related to empowerment through patient education, and specifically, on its influence on knowledge, self-efficacy, self-determination, autonomy, self-care behavior, self-care activity, self-care management, independency, mastery, empowerment, and outcome expectations.

According to the types of studies identified through the literature review, an additional focus was placed on intervention studies (clinical trials) to investigate the effects of educational interventions on outcomes related to empowerment. Studies were excluded if they were carried out in hospitals, institutions for mentally disabled people, or in communitydwelling populations. Studies that were conducted in mixed settings (eg, nursing homes and day centers) were excluded if it was not possible to extract data about the population of interest. Studies that described outcomes that were not explicitly related to empowerment, such as compliance with treatment or physical parameters (eg, grip strength), and that did not consider self-care or independency were also excluded. ${ }^{24}$ Interventions that could be used to empower or educate (nursing) staff exclusively were considered to be beyond the scope of this review and were excluded.

\section{Assessment of potential bias with regard to the studies included}

Two authors assessed the quality of the included studies independently. Disagreement was resolved by consensus.
Table 2 Levels of evidence ${ }^{27}$

\begin{tabular}{ll}
\hline Level I & Systematic reviews of RCTs \\
Level $2^{\mathrm{a}}$ & RCTs or observational studies with dramatic effects \\
Level $3^{\mathrm{a}}$ & Non-randomized controlled trials \\
Level $4^{\mathrm{a}}$ & Case series \\
Level $5^{\mathrm{a}}$ & Mechanism-based reasoning \\
\hline
\end{tabular}

Note: aLevel may be downgraded on the basis of study quality. Data from CEBM. Available from: http://www.cebm.net/index.aspx?. $=5653 .{ }^{27}$

Abbreviation: RCTs, randomized controlled trials.

Intervention studies with a control group were assessed using the Critical Appraisal Worksheet for Therapy Studies. ${ }^{26}$ The level of evidence was assigned according to the Oxford Centre for Evidence-Based Medicine (OCEBM) Levels of Evidence Working Group (Table 2). ${ }^{27}$ To appraise case-series studies, the Three-Minute Checklist was used. ${ }^{28}$ There is no unity in the classification of case series (also called time series). According to Melnyk and Fineout-Overholt, they belong to quasiexperimental designs (intervention studies); in contrast, Chan and Bhandari assign them to observational studies. ${ }^{28,29}$ Because they are mentioned in the evidence hierarchy of the OCEBM Levels of Evidence Working Group, case series were handled as intervention studies in this review and not excluded. ${ }^{27}$

\section{Data extraction and synthesis}

Data were extracted about the design, participants, type of intervention (including the application of the intervention), control of the intervention, outcome measures, and the duration of the study, using the Cochrane Review data extraction method, from each intervention study included..$^{30}$

The results of the studies were grouped according to the main empowering outcomes identified, and the effects were presented as $P$-values (if possible). Only outcomes referring to empowerment were considered in the results of intervention studies. As the interventions were expected to be heterogeneous, results were described narratively.

\section{Results}

A total of 427 studies were identified as a result of the systematic database search. In addition, four studies were identified by screening the reference lists of the included studies and reviews. The SIGLE and Google Scholar search did not lead to the identification of additional relevant articles. After removing duplicates, 258 articles were excluded on the basis of their titles and abstracts because they did not address the research question or inclusion criteria. The full texts of the remaining 26 articles were examined in detail, eleven of which fulfilled the inclusion criteria. One study was subsequently excluded because no data on group comparison were presented in the results and the "before"and-"after" comparison data described were not traceable. ${ }^{31}$ 
In total, ten studies were included that directly addressed the research question.

A flow diagram of the study selection based on the PRISMA statement is presented in Figure 1.32

\section{Characteristics of the included studies}

Of the ten intervention studies, seven were randomized controlled trials. Four of the studies used cluster randomization, ${ }^{33-36}$ another three used individual randomization, ${ }^{37-39}$ and three were quasi-experimental studies: a clinical controlled trial without randomization and two case-series studies. ${ }^{40-42}$ Seven studies had been conducted with residents living in nursing homes, ${ }^{33,37-42}$ and three, in assisted living facilities and residential care homes. ${ }^{34-36}$

The sample size ranged from 21 to 1,042 residents. The majority of the residents included in the studies were female (between 64 and 93), and the mean age of the participants ranged from 77 to 88 years, with the exception of the study by Bonanni et al where no mean age was described. ${ }^{42}$

In nearly all trials, residents with cognitive impairments (including mild stages of dementia) were included. ${ }^{33,35-39,41,42}$ The interventions were performed every day (integrated into nursing daily practice), one to two times a week, or five times over a 3-month period, and were made for periods of 3 weeks to 12 months.

\section{Educational interventions to empower residents}

The interventions performed were all complex and differed to varying extents but also shared similarities. In two interventions, interactive group education sessions were held to provide knowledge on disease and self-management strategies. ${ }^{39,40}$ These were supported by customized counseling based on needs and preferences. In the group sessions described by Park et al, personal experiences were also discussed. ${ }^{40}$

In three studies, restorative care interventions were used to educate residents, and in one study, function-focused care interventions. ${ }^{33,34,41,42}$ These interventions, which used motivational strategies, were designed to help residents attain and maintain their highest possible functional and physical status. In the intervention published by Resnick et al, for example, residents were encouraged to do simple tasks by themselves, such as getting into bed. Enough time was given

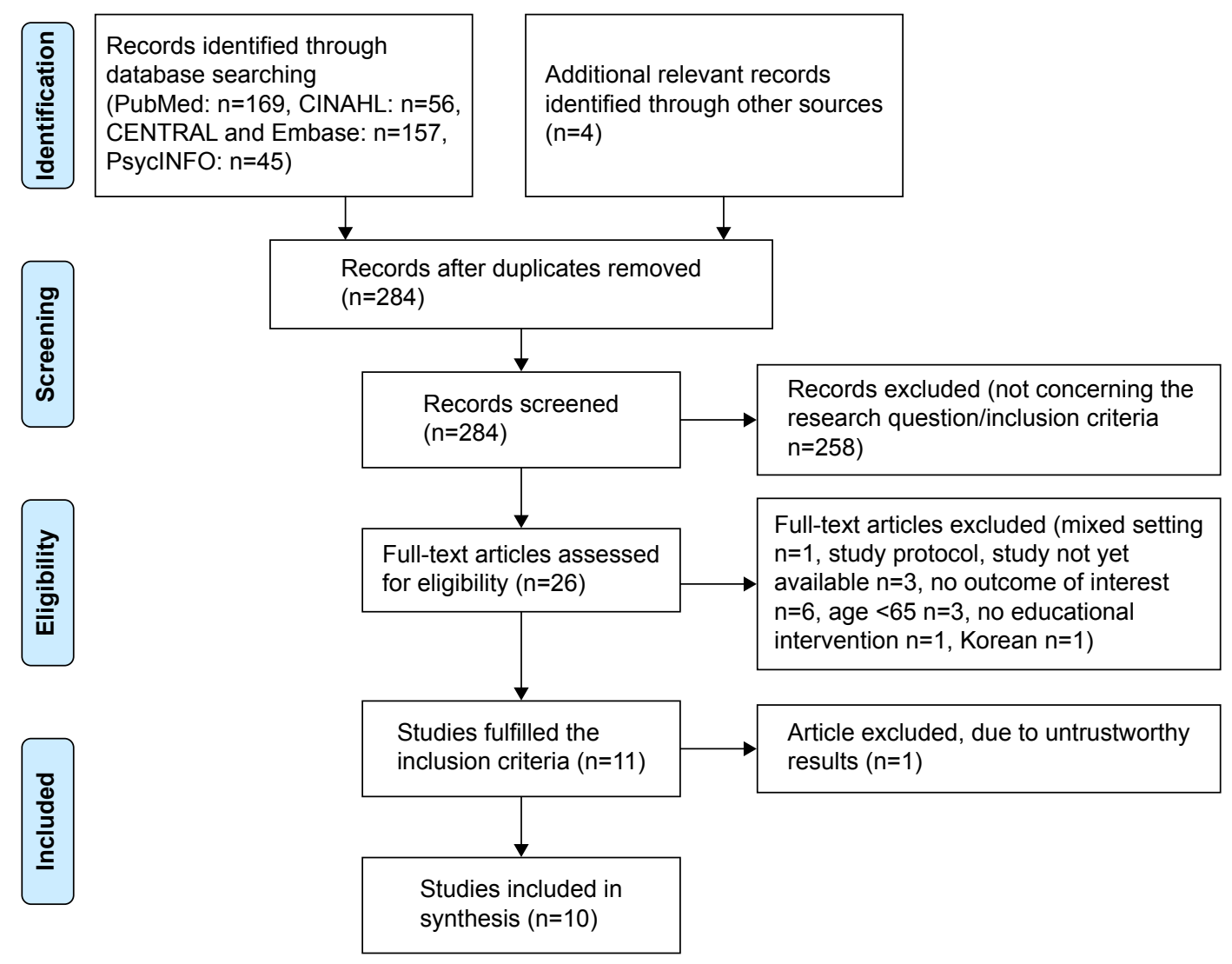

Figure I Flow diagram of study selection. 
to perform the tasks, give step-by-step cues on how to do them, and when needed, to guide the residents to facilitate their independent activity. ${ }^{33}$

Motivational strategies such as positive feedback, motivational self-management tips, and motivational interviews were also core concepts of other interventions. ${ }^{39,40}$ Another strategy that was commonly used was goal setting on the basis of residents' needs and motivation levels and the development of an individually tailored plan to meet the goals. ${ }^{33-36,39-41}$ Park et al also identified barriers that hindered the action plan. ${ }^{40}$ Problem-solving skill training, helping residents identify problems, set goals, and solve problems in small steps, and training in reasoning strategies were main interventions used by Williams et al to promote the self-care level. ${ }^{35}$ Acquired reasoning strategies were applied during everyday situations and included scanning information, reading aloud, underlining or highlighting key information, and breaking information into smaller pieces. ${ }^{35}$ The interventions provided by Andresen et al were based on the residents' individual wishes, and therefore, difficult to extrapolate. ${ }^{37}$

Printed educational material was used in addition to verbal education in three studies, and in two studies, posters were placed in the residents' rooms to act as reminders and motivators. ${ }^{33-35,40,41}$ Most interventions were carried out by nursing staff. In the restorative care interventions as well as the function-focused care interventions, an emphasis was placed on educating nursing staff about motivational techniques based on self-efficacy and supplying nurses with specific training to support the nursing staff while introducing motivational interventions. ${ }^{33,34,41,42}$ A multi-professional approach, whereby the interdisciplinary team, residents, and families were educated, was used in the study by Resnick et al. ${ }^{34}$ In one study, the intervention was also delivered by occupational therapists. ${ }^{36}$ The short descriptions of the studies included are given in Table 3.

\section{Quality of the intervention studies included}

According to the levels of evidence, six studies were assigned as Level 2 studies, two as Level 3 studies, and two as Level 4 studies. ${ }^{27}$ The quality of the included studies, which included control groups, is reported in Table 4, and the quality of the case-series studies, in Table 5.

The randomization of residents/clusters to the groups was described in all Level 2 studies. In two studies, randomization was conducted by the use of computer-generated random numbers, and in the others, by statistician-generated random numbers and by lot. ${ }^{35-37,39}$ Resnick et al did not describe how the randomization was conducted. ${ }^{33,34}$ Allocation concealment was described in the studies of Sackley et al, Andresen et al, and Park and Chang. ${ }^{36,37,39}$

The baseline characteristics of the intervention and control groups were comparable in four Level 2 studies. $^{33,36,37,39}$ In the study by Williams et al, significant differences between the groups were found in one primary outcome (Every Day Problems Test for Cognitively Challenged Elders score), but these were controlled in analysis models that were used to examine change over time. ${ }^{35}$ Significant differences with regard to the outcomes expectations and number of diagnoses were detected in the study by Resnick et al. According to authors, the results did not differ when the outcomes had been controlled. ${ }^{34}$

In all Level 2 studies, there was no indication that participants in different groups received additional treatments apart from the interventions. In the study conducted by Andresen et al, the authors mentioned that it might be challenging for the staff to distinguish participants from one another in terms of intervention, which may have biased the results. ${ }^{37}$

The analyses were conducted according to an intentionto-treat paradigm in several trials, but a comprehensible description of how the paradigm was performed was only available in two trials. ${ }^{34,37}$ The data analyses described in the remaining studies were designated as per-protocol analyses, since no descriptions of the intention-to-treat paradigm were made, and the dropouts were evidently not included in the follow-up analyses. ${ }^{33,35,36,38,39}$ Blinding of the outcome assessor was described in four trials. ${ }^{33,36,37,39}$

The study by Park et al was assigned as a Level 3 study because no randomization was conducted. As there were no dropouts from this study, an intention-to-treat analytical method is presumed to have been used. ${ }^{40}$ The study by Vinsnes et al had to be downgraded due to the presence of several serious flaws, such as the fact that no baseline characteristics were illustrated. ${ }^{38}$

There were several limitations to the study by Bonanni et al, such as the lack of information about the inclusion and exclusion criteria and the number of residents included in the outcome analysis. ${ }^{42}$

\section{Effects of the interventions}

Empowering outcomes addressed in the intervention studies could be categorized into self-efficacy, self-care activities/management/behavior, autonomy, and outcome expectations. 


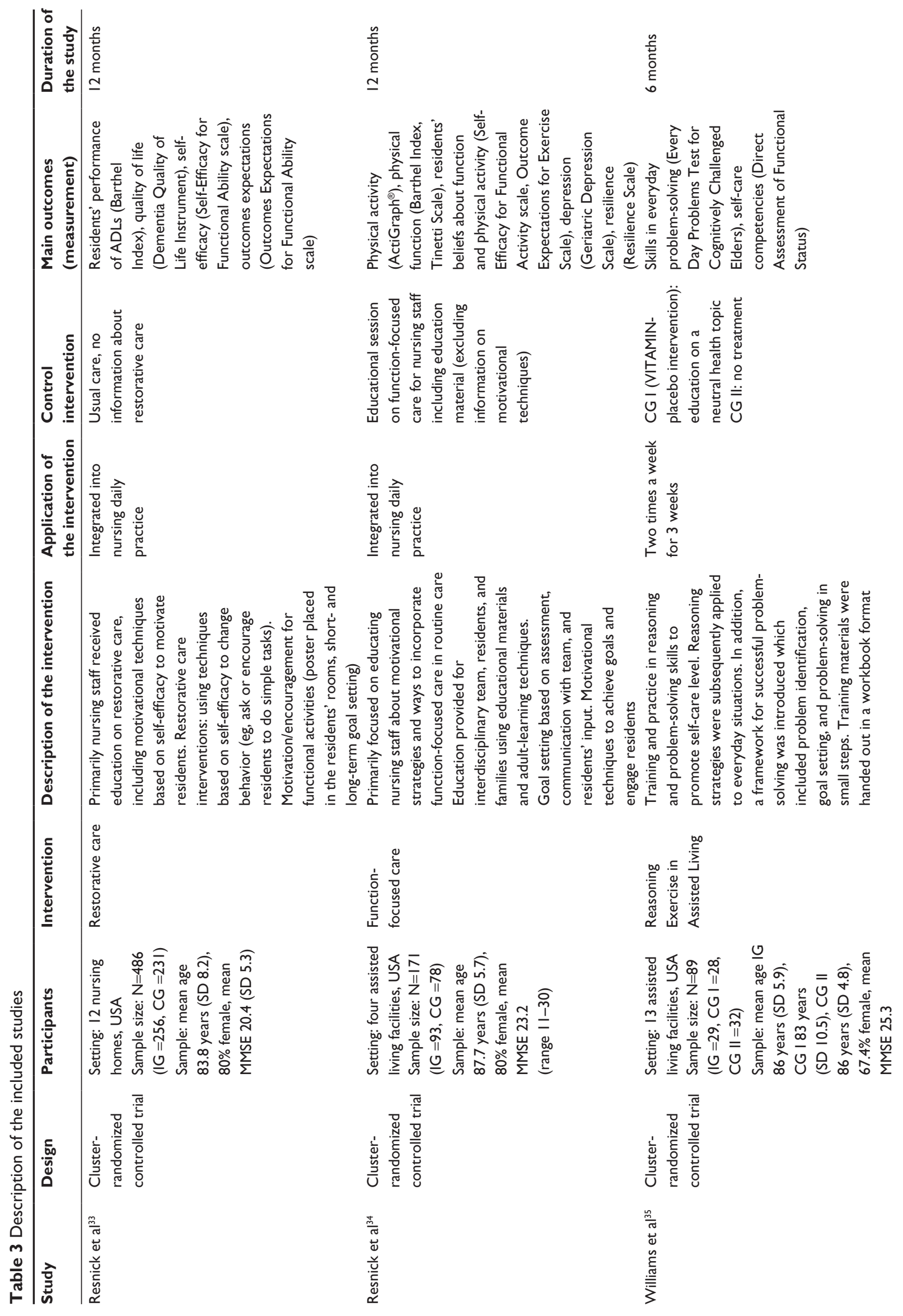


$\stackrel{n}{ \pm}$
$\stackrel{5}{0}$
$\stackrel{1}{E}$
$\simeq$

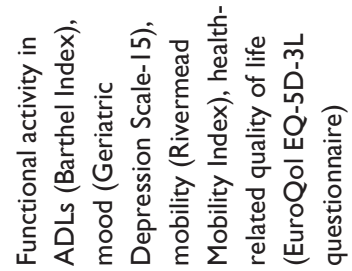

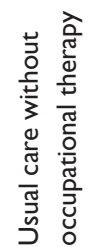

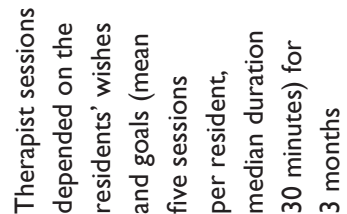

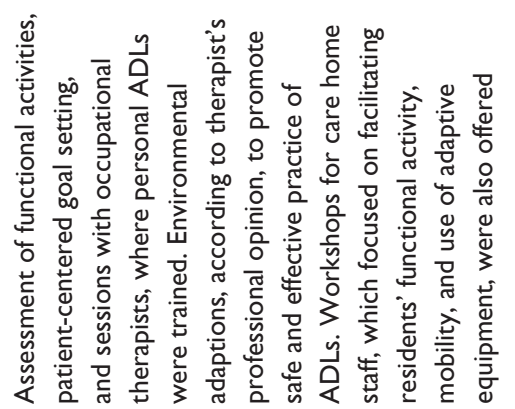

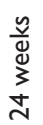

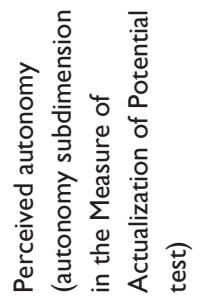

$n$
$\stackrel{n}{H}$
है
m

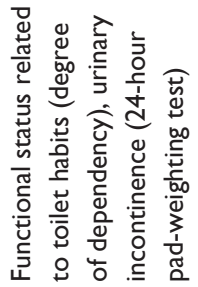

$\sum_{\infty}^{\frac{n}{d}}$

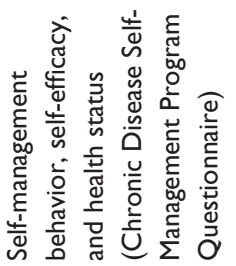

$\frac{\sqrt[0]{\frac{0}{3}}}{\frac{0}{3}}$

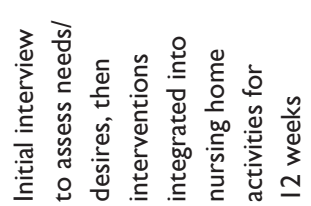

$\frac{\sqrt[3]{3}}{\frac{3}{3}}$

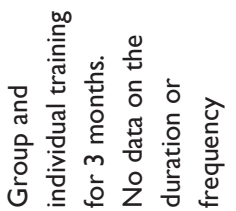

$\frac{\sqrt[0]{7}}{\frac{0}{3}}$

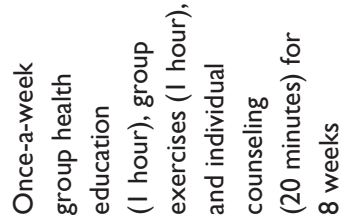

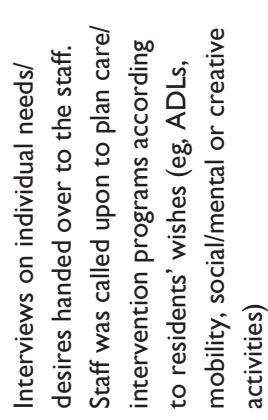
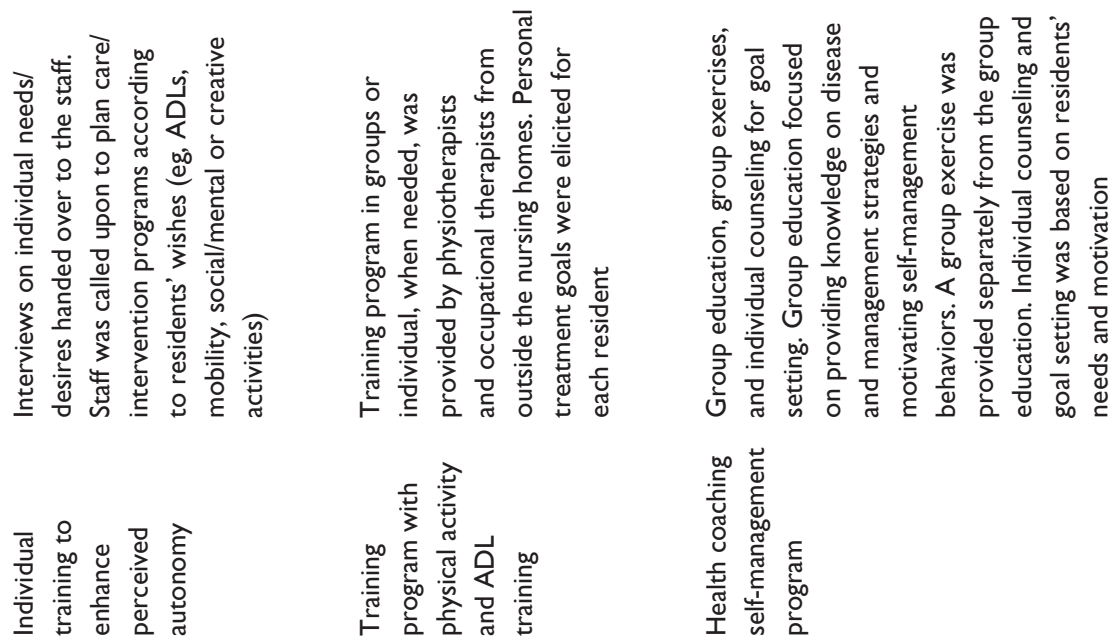

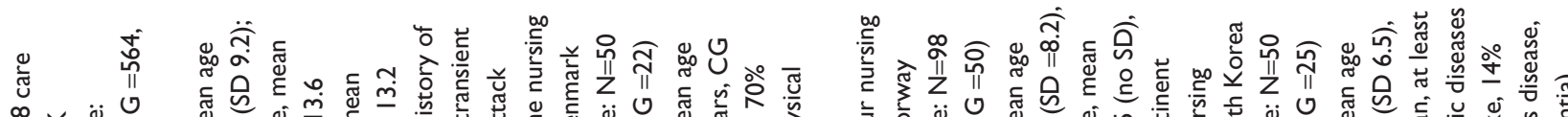

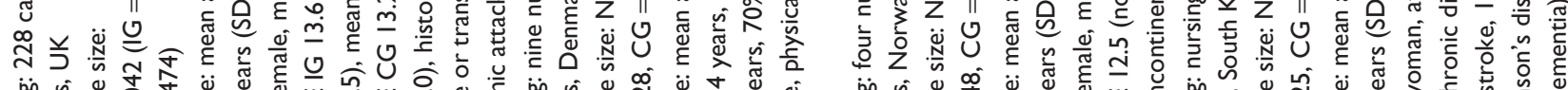
. 焉
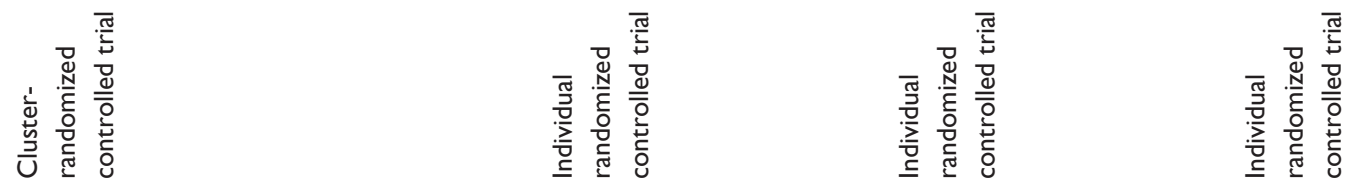

$\frac{0}{\pi}$
$\frac{\pi}{0}$
$\frac{d}{v}$
$\frac{0}{0}$

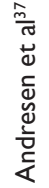

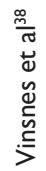

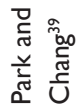




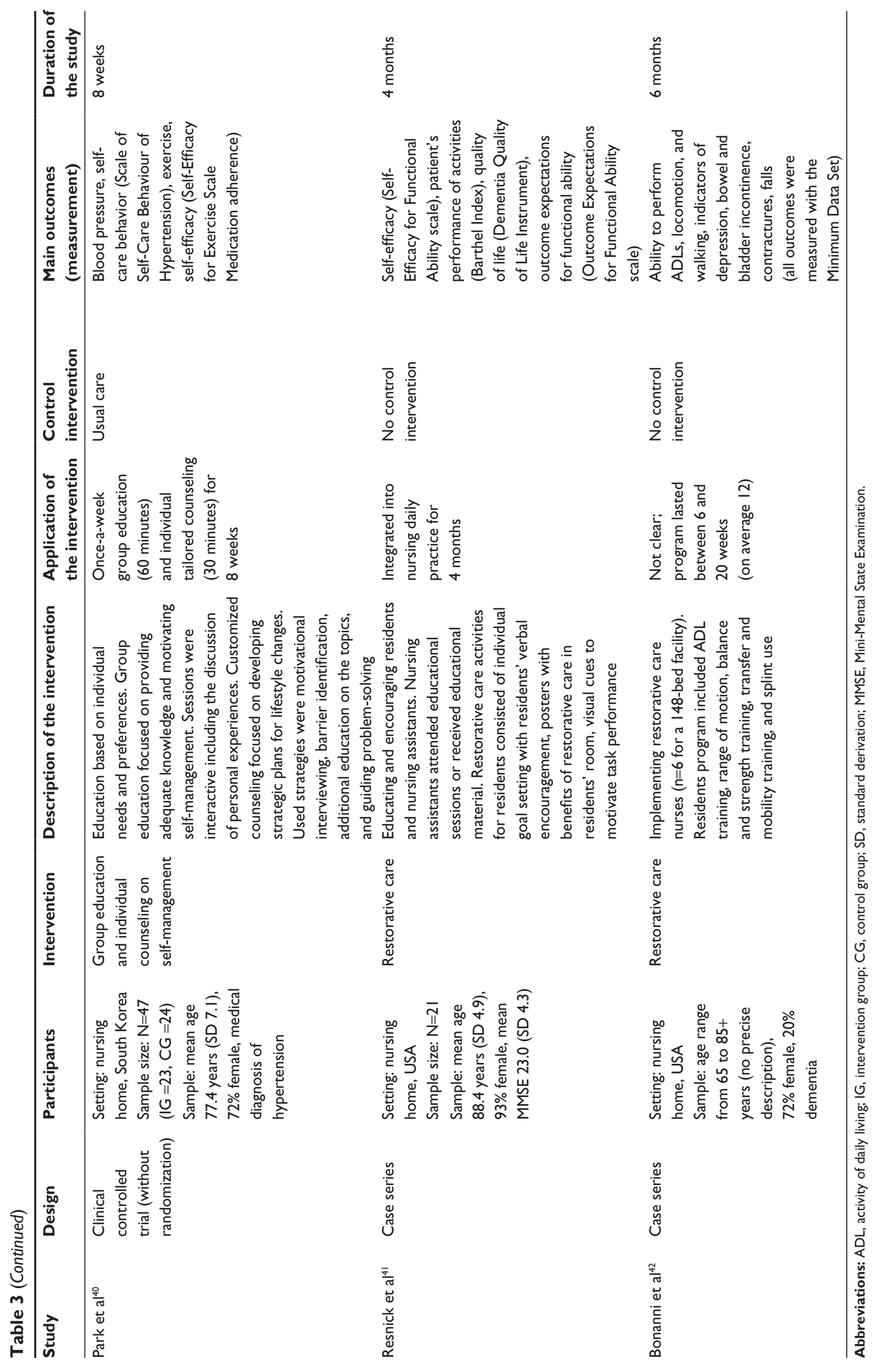


Table 4 Quality of the included studies with control groups (including levels of evidence)

\begin{tabular}{|c|c|c|c|c|c|c|c|c|}
\hline Internal validity of the therapy studies ${ }^{26}$ & $\begin{array}{l}\text { Resnick } \\
\text { et } \mathbf{a l}^{33}\end{array}$ & $\begin{array}{l}\text { Resnick } \\
\text { et } \mathbf{a l}^{34}\end{array}$ & $\begin{array}{l}\text { Williams } \\
\text { et } \mathrm{al}^{35}\end{array}$ & $\begin{array}{l}\text { Sackley } \\
\text { et } \mathbf{a l}^{36}\end{array}$ & $\begin{array}{l}\text { Andresen } \\
\text { et } \mathbf{a l}^{37}\end{array}$ & $\begin{array}{l}\text { Park and } \\
\text { Chang }^{39}\end{array}$ & $\begin{array}{l}\text { Park } \\
\text { et } \mathbf{a l}^{40}\end{array}$ & $\begin{array}{l}\text { Vinsnes } \\
\text { et } \mathbf{a l}^{38}\end{array}$ \\
\hline $\begin{array}{l}\text { Was the assignment of patients (clusters) to } \\
\text { treatments randomized? }\end{array}$ & Yes & Yes & Yes & Yes & Yes & Yes & No & Yes \\
\hline Were the groups similar at the beginning of the trial? & Yes & $\mathrm{No}^{\mathrm{a}}$ & $\mathrm{No}^{\mathrm{b}}$ & Yes & Yes & Yes & Yes & Unclear \\
\hline $\begin{array}{l}\text { Other than the allocated treatment, were the } \\
\text { groups treated equally? }\end{array}$ & Yes & Yes & Yes & Yes & Yes $^{c}$ & Yes & Yes & Yes \\
\hline $\begin{array}{l}\text { Were all the patients who entered the trial } \\
\text { accounted for, and were they analyzed in the groups } \\
\text { to which they were randomized? }\end{array}$ & No & Yes & No & No & Yes & No & Yes & No \\
\hline $\begin{array}{l}\text { Were the measures objective or were the patients } \\
\text { and clinicians "blinded" to the treatment received? }\end{array}$ & Yes & Unclear & Unclear & Yes & Yes & Yes & No & Unclear \\
\hline Levels of evidence $^{27}$ & 2 & 2 & 2 & 2 & 2 & 2 & 3 & $3^{d}$ \\
\hline
\end{tabular}

Notes: aBaseline of significant differences (although authors stated that results did not differ once controlled). 'Baseline group differences but controlled using analytical models examining change over time. 'The control group may also potentially have received the intervention. 'Level of evidence downgraded due to serious flaws in the study.

Self-efficacy could be significantly improved by interventions that included interactive group education and individually tailored counseling based on needs and preferences. ${ }^{39,40}$ The restorative care and function-focused care interventions had no significant effects on residents' self-efficacy. ${ }^{33,34,41}$

Outcomes according to self-care were those most commonly examined in the intervention studies. These could also be significantly improved by group education and individual counseling, and in addition, self-care competencies and skills in everyday problem-solving improved significantly by conducting reasoning exercises and training in problemsolving. ${ }^{35,39,40}$ A long-term effect on physical function in activities of daily living (ADLs) could be detected as a result of function-focused care interventions, but the effect did not immediately take place after providing the intervention. ${ }^{34}$ Bonanni et al reported an improvement in the performance of ADLs during the 3- and 6-month follow-up, but no $P$-value was stated. ${ }^{42}$ No significant improvement in self-care was observed as a result of restorative care interventions,

Table 5 Quality of the case series studies included (including levels of evidence)

\begin{tabular}{lll}
\hline The three-minute checklist & Resnick $^{\mathbf{4 1}}$ & Bonanni $^{\mathbf{4 2}}$ \\
\hline Clear study objective/question & Yes & Partially \\
Well-defined study protocol & Yes & Partially \\
$\begin{array}{l}\text { Explicit inclusion and exclusion criteria for } \\
\text { study participants }\end{array}$ & Yes & No \\
$\begin{array}{l}\text { Specified time interval for patient recruitment } \\
\text { Consecutive patient enrolment }\end{array}$ & No & No \\
Clinically relevant outcomes & Unclear & Unclear \\
Prospective outcome data collection & Yes & Yes \\
High follow-up rate & Yes & Yes \\
Levels of Evidence & No & Unclear \\
\hline
\end{tabular}

occupational therapy intervention, and physical activity and ADL training designed to enhance independency in toilet habits. ${ }^{33,36,38,41}$

Neither perceived autonomy nor outcome expectations could be significantly improved by any educational intervention. ${ }^{33,34,37,41}$ The main results of the interventions are presented in Table 6 .

\section{Discussion}

Only a few studies could be identified that described educational interventions to empower nursing home residents, citing mainly good-to-moderate evidence. However, despite the low number of studies identified, meaningful preliminary findings can be summarized. The results of our findings are shown in Figure 2 in the form of preliminary recommendations.

Several intervention studies of good quality demonstrated that older nursing home residents can be effectively educated to achieve significant effects, mostly with regard to outcomes related to self-care behavior. Effective interventions were quite variable, but all interventions were (at least in part) individually tailored, interactive, continuous (ie, not conducted at a single time point), encouraging, and motivational. These seem to be the most important and effective strategies to use when educating older residents.

One core strategy that was used in several studies was to motivate and encourage residents. Providing positive feedback can strengthen the residents' personal resource and reduce barriers that hinder their mastery of a task or independence. ${ }^{24}$ Qualitative studies have shown that many nursing home residents lack confidence to do tasks by themselves, and that positive reinforcement is needed. ${ }^{9,10}$ In order to be able to motivate and encourage residents, nurses must 


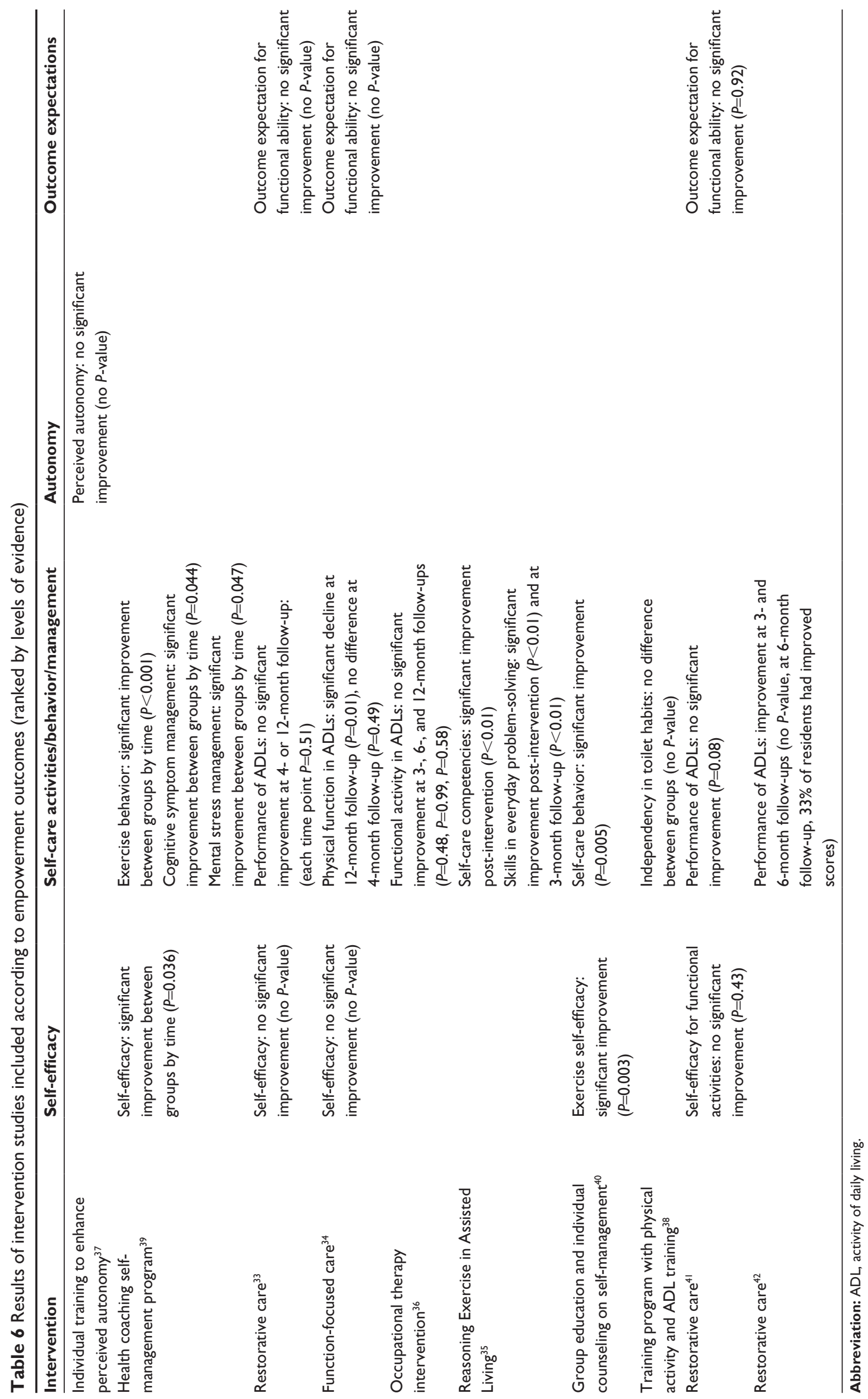




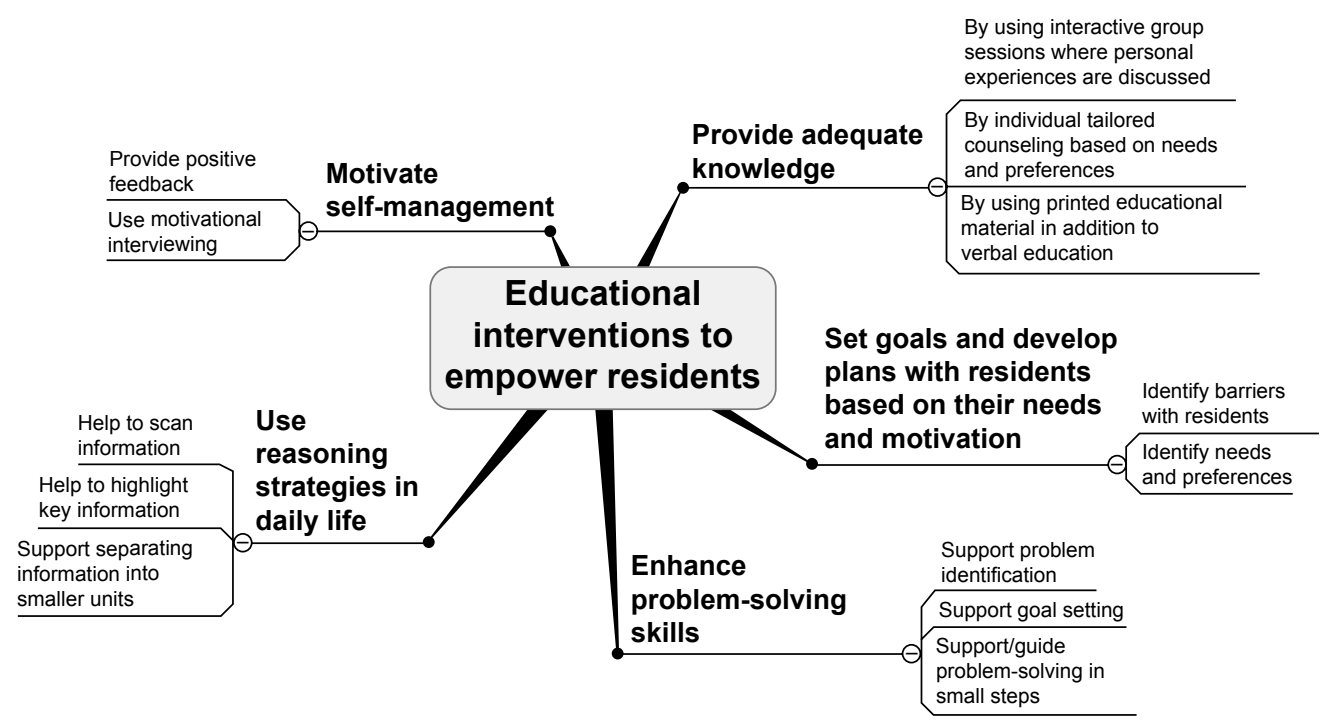

Figure 2 Summary of effective educational interventions to empower nursing home residents.

be themselves motivated and empowered.${ }^{43}$ Education of the nursing staff on motivational and encouraging techniques was part of the intervention studies by Resnick et al. ${ }^{33,34}$

However, these motivational and encouraging techniques alone cannot significantly improve self-efficacy, as the studies by Resnick et al have shown. ${ }^{33,34}$ By additionally setting individually tailored goals and developing strategic plans with residents based on their needs, significant improvement in self-efficacy could be reached. ${ }^{39,40}$ This combination of strategies may be crucial to affect self-efficacy. Although the high-quality study by Andresen et al did not report significant effects on perceived autonomy, the study showed that older nursing home residents are able to clearly express wishes. ${ }^{37}$ Gaining insight into the older patients' needs, priorities, and experiences is also mentioned and of high importance in reviews on principles of learning in older people. ${ }^{6,24,25} \mathrm{~A}$ fundamental skill that nurses should develop, in order to ensure resident-centeredness according to Hage and Lorensen, is to be able to listen to the older people and be willing to respect their experiences, values, interests, and goals. ${ }^{24}$ This requires nurses to treat all residents as equal, an ascribed behavior of nurses. ${ }^{44}$ Providing resident-centered care, in turn, can positively impact the nurses' job satisfaction and work conditions. ${ }^{23}$

Interventions that were integrated into daily life had less significant outcomes than interventions that were based on regular meetings, including group sessions. The more highly structured approach may lead to more benefits for residents, as recent patient education research on diabetes and anaphylaxis has shown. ${ }^{45,46}$ Group sessions, in addition, can stimulate communication and support feelings of social belonging, which facilitate empowerment. ${ }^{47}$ However, we note that trials with the more highly structured interventions had shorter follow-ups, and no long-term effects were generated. Therefore, the long-term effects of these interventions are still unclear.

In three studies, printed educational materials were used in addition to verbal education. By the provision of different types of education (printed information, verbal education), older persons' learning skills can be matched. ${ }^{25}$ This requires analyses of the learning styles/strategies of older people to be conducted during the educational process.

None of the included studies measured empowerment using a scale that had been specifically developed for this task, although such scales are available, six of which are generic and one of which has been designed especially for older people. ${ }^{17,18,48,49}$ Furthermore, none of the studies investigated the effects of educational interventions on overall knowledge. This is interesting because attainment of knowledge has been a primary outcome of educational interventions reported for other population groups. ${ }^{50}$ Knowledge that helps people meet their needs, expectations, or preferences is seen as fundamental to becoming empowered. ${ }^{51}$ As the mean age of the participants in the studies was high, and several studies included cognitively impaired residents, knowledge tests were perhaps not considered appropriate for the target group. Instead, the studies focused on skills, competences, and independency in ADLs.

The level of evidence in the studies included ranged between 2 and 4 . Interestingly, the high-quality studies more frequently achieved significant results than studies with lower quality. ${ }^{38,41}$ The improved scores in the ADL performance in 
the study by Bonanni et al must be interpreted with caution because there were several flaws in the study design. ${ }^{42}$ The majority of the included studies were cluster-randomized trials, with facilities as clusters. There was no indication that the participants in the different groups were treated differently apart from the allocated interventions. However, because no information on the "usual care" or the level of standardization of care in the participating facilities was given, differences in the residents' perception of the care received may have influenced the outcomes.

Neither the occupational therapist visits, which were described in a high-quality study by Sackley et al nor the individual training to enhance autonomy in the very high-quality study performed by Andresen et al resulted in observable empowerment. ${ }^{36,37}$ The intervention schedule used in the study by Sackley et al, with mean five sessions over 3 months, could have been too infrequent for the frail nursing home residents, many of whom were cognitively impaired and severely depressed. ${ }^{36}$ In the study by Andresen et al, no significant differences in the main outcome, perceived autonomy, were detected between groups, and this may have been due to problems encountered in distinguishing participants from one another in terms of the intervention. ${ }^{37}$

\section{Limitations}

Some limitations may have influenced the interpretation of these reported results. On the basis of the available evidence, no consensus on the outcomes of empowerment could be reached. During this study, we used the empowering outcomes described by Heikkinen et al, Gibson, Aujoulat et al, Falkner, and Anderson and Funell. ${ }^{14-19}$ This list of terms may be further extended in future studies. According to the core principles of empowerment, self-care activities or selfcare management should only be considered to be relevant outcomes of empowerment if they result from a process of self-determination, whereby residents choose their own goals and strategies to reach these goals. ${ }^{17}$ Although the residents' could help choose their goals in most of the intervention studies, the degree of self-determination needed to reach these goals was not measured in these studies. Therefore, it is still unclear whether enhanced self-management skills lead to enhanced empowerment.

\section{Conclusion and recommendations}

Empowerment is as fundamental to people of all ages as dignity and contributes to successful learning in older nursing home residents. Individually tailored, interactive, continuous, and clearly structured educational strategies, including group education, individual counseling, and the use of motivational and encouragement techniques, may effectively help nursing home residents become more highly empowered. Preliminary findings have shown that empowering strategies used by nurses can support residents in their personal growth and facilitate their self-determination. Educational interventions can be more effectively adapted to meet residents' needs by analyzing the learning styles/strategies of older people. Further research on empowerment in the nursing home environment is needed. In particular, empowering scales should be used, and correlations between outcomes and measures of empowerment, such as self-determination, should be more carefully assessed.

\section{Disclosure}

The authors report no conflicts of interest in this work.

\section{References}

1. Jeon MY, Jeong H, Petrofsky J, Lee H, Yim J. Effects of a randomized controlled recurrent fall prevention program on risk factors for falls in frail elderly living at home in rural communities. Med Sci Monit. 2014; 20:2283-2291.

2. Hageman PA, Pullen CH, Hertzog M, Boeckner LS. Effectiveness of tailored lifestyle interventions, using web-based and print-mail, for reducing blood pressure among rural women with prehypertension: main results of the Wellness for Women: DASHing towards Health clinical trial. Int J Behav Nutr Phys Act. 2014;11:148.

3. Kuerbis AN, Yuan SE, Borok J, et al. Testing the initial efficacy of a mailed screening and brief feedback intervention to reduce at-risk drinking in middle-aged and older adults: the comorbidity alcohol risk evaluation study. J Am Geriatr Soc. 2015;62(3):321-326.

4. World Health Organization. Health education: theoretical concepts, effective strategies and core competencies. Cairo: Regional Office for the Eastern Mediterranean; 2012. Available from: http://applications.emro. who.int/dsaf/EMRPUB_2012_EN_1362.pdf. Accessed May 23, 2016.

5. European Commission. Investing in health. Social Investment Package. Commission staff working document. Brussels: European Commission; 2013. Available from: http://ec.europa.eu/health/strategy/docs/ swd_investing_in_health_en.pdf. Accessed May 23, 2016.

6. Stevens B. How seniors learn. Issue Brief Cent Medicare Educ. 2003; 4(9): $1-8$.

7. Florin J, Ehrenberg A, Ehnfors M. Patient participation in clinical decision-making in nursing. A comparative study of nurses' and patients' perceptions. J Clin Nurs. 2006;15(12):1498-1508.

8. Leino-Kilpi H, Heikkinnen K, Hiltunen A, et al. Preference for information and behavioural control among adult ambulatory surgical patients. Appl Nurs Res. 2009;22(2):101-106.

9. Schoberer D, Breimaier HE, Mandl M, Halfens RJG, Lohrmann C. Involving the consumers: an exploration of users' and caregivers' needs and expectations on a fall prevention brochure: a qualitative study. Geriatr Nurs. 2016;37(3):207-214.

10. Yardley L, Donovan-Hall M, Francis K, Todd C. Older people's views of advice about falls prevention: a qualitative study. Health Educ Res. 2006;21(4):508-517.

11. McMahon S, Talley KM, Wyman JF. Older people's perspectives on fall risk and fall prevention programs: a literature review. Int J Older People Nurs. 2011;6(4):289-298.

12. McInnes E, Askie L. Evidence review on older people's views and experience of falls prevention strategies. Worldviews Evid Based Nurs. 2004;1(1):20-37. 
13. Kuokkanen L, Leino-Kilpi H. Power and empowerment in nursing: three theoretical approaches. $J$ Adv Nurs. 2000;31(1):235-241.

14. Heikkinen K, Leino-Kilpi H, Hiltunen A, et al. Ambulatory orthopaedic surgery patients' knowledge expectations and perceptions of received knowledge. J Adv Nurs. 2007;60(3):270-278.

15. Heikkinen K, Leino-Kilpi H, Nummela T, Kaljonen A, Salantera S. A comparison of two educational interventions for the cognitive empowerment of ambulatory orthopaedic surgery patients. Patient Educ Couns. 2008;73(2):272-279.

16. Gibson CH. A concept analysis of empowerment. J Adv Nurs. 1991; 16(3):354-361.

17. Aujoulat I, d'Hoore W, Deccache A. Patient empowerment in theory and practice: polysemy or cacophony? Patient Educ Couns. 2007;66(1): $13-20$.

18. Falkner M. A measure of patient empowerment in hospital environments catering for older people. $J$ Adv Nurs. 2001;34(5):676-686.

19. Anderson RM, Funell MM. Patient empowerment: myths and misconceptions. Patient Educ Couns. 2010;79(3):277-282.

20. Bandura A. Health promotion by social cognitive means. Health Educ Behav. 2004;31(2):143-164.

21. Tu YC, Wang RH, Yeh SH. Relationship between perceived empowerment care and quality of life among elderly residents within nursing homes in Taiwan: a questionnaire survey. Int J Nurs Stud. 2006;43(6) 673-680

22. Slettebo A. Empowerment in nursing homes: lessons for district nursing? Br J Community Nurs. 2013;11(3):115-118.

23. Brownie $S$, Nancarrow $S$. Effects of person-centered care on residents and staff in aged-care facilities: a systematic review. Clin Interv Aging. 2013;8:1-10

24. Hage AM, Lorensen M. A philosophical analysis of the concept empowerment; the fundament of an education-programme to the frail elderly. Nurs Philos. 2005;6(4):235-246.

25. Suter PM, Suter N. Timeless principles of learning - a solid foundation for enhancing chronic disease self-management. Home Healthc Nurse. 2008;26(2):82-88.

26. Centre for Evidence-based Medicine. Critical appraisal worksheets therapy studies. Oxford: University of Oxford; 2005. Available from: http://www.cebm.net/wp-content/uploads/2014/06/RCT_Appraisal_ sheets_2005_English-2.docx. Accessed May 23, 2016.

27. OCEBM Levels of Evidence Working Group. The Oxford 2011 levels of evidence. Oxford: Oxford Centre for Evidence-Based Medicine; 2011. Available from: http://www.cebm.net/index.aspx?o=5653. Accessed May 23, 2016

28. Chan K, Bhandari M. Three-minute critical appraisal of a case series article. Indian J Orthop. 2011;45(2):103-104.

29. Melnyk BM, Fineout-Overholt E. Evidence-Based Practice in Nursing \& Healthcare. 2nd ed. Philadelphia, PA: Lippincott, Williams \& Wilkins; 2011.

30. Higgins JPT, Green S, editors. Cochrane Handbook for Systematic Reviews of Interventions. Version 5.1.0. [updated March 2011]. London: The Cochrane Collaboration; 2011. Available from: http://handbook. cochrane.org/. Accessed May 23, 2016.

31. Chang SH, Fang MC, Chang HY. Enhancing three bliss concepts among nursing home elders in Taiwan. J Clin Nurs. 2010;19(5-6):682-690.

32. Moher D, Liberati A, Tetzlaff J, Altman DG; for PRISMA Group Preferred Reporting Items for Systematic Reviews and Meta-Analyses: the PRISMA statement. Int J Surg. 2010;8(5):336-341.
33. Resnick B, Gruber-Baldini AL, Zimmerman S, et al. Nursing home resident outcomes from the Res-Care intervention. $J$ Am Geriatr Soc. 2009;57(7):1156-1165.

34. Resnick B, Galik E, Gruber-Baldini A, Zimmerman S. Testing the effect of function-focused care in assisted living. J Am Geriatr Soc. 2011;59(12):2233-2240.

35. Williams K, Herman R, Bontempo D. Reasoning Exercises in Assisted Living: a cluster randomized trial to improve reasoning and everyday problem solving. Clin Interv Aging. 2014;9:981-996.

36. Sackley CM, Walker MF, Burton CR, et al. An occupational therapy intervention for residents with stroke related disabilities in UK care homes $(\mathrm{OTCH})$ : cluster randomised controlled trial. BMJ. 2015; 350:h468.

37. Andresen M, Runge U, Hoff M, Puggaard L. Perceived autonomy and activity choices among physically disabled older people in nursing home setting: a randomized Trial. J Aging Health. 2009;21(8):1133-1158.

38. Vinsnes AG, Helbostad JL, Nyrønning S, Harkless GE, Granbo R, Seim A. Effect of physical training on urinary incontinence: a randomized parallel group trial in nursing homes. Clin Interv Aging. 2012;7: 45-50.

39. Park YH, Chang HK. Effect of a health coaching self-management program for older adults with multimorbidity in nursing homes. Patient Prefer Adherence. 2014;8:959-970.

40. Park YH, Chang HK, Kim JS, Kwak JS. Patient-tailored self-management intervention for older adults with hypertension in a nursing home. J Clin Nurs. 2013;22(5-6):710-722.

41. Resnick B, Simpson M, Bercovitz A, et al. Pilot testing of the restorative care intervention: impact on residents. J Gerontol Nurs. 2006; 32(3):39-47.

42. Bonanni DR, Devers G, Dezzi K, et al. A dedicated approach to restorative nursing. J Gerontol Nurs. 2009;35(1):37-44.

43. Campbell SL. Empowering nursing staff and residents in long-term care. Geriatr Nurs. 2003;24(3):170-175.

44. Kuokkanen L, Leino-Kilpi H. The qualities of an empowered nurse and the factors involved. J Nurs Manag. 2001;9(5):273-280.

45. Carey M, Khunti K, Davies MJ. Structured education in diabetes: a review of the evidence. Diabetes Prim Care. 2012;14(3):154-162.

46. Brockow K, Schallmayer S, Beyer K, Biedermann T, Fischer J, Gebert N; for working group on anaphylaxis training and education (AGATE). Effects of a structured educational intervention on knowledge and emergency management in patients at risk for anaphylaxis. Allergy. 2015;70(2):227-235.

47. Baur VE, Abma TA, Boelsma F, Woelders S. Pioneering partnerships. Resident involvement from multiple perspectives. J Aging Stud. 2013;27(4):358-367.

48. Herbert RJ, Gagnon AJ, Rennick JE, O'Loughlin JL. A systematic review of questionnaires measuring health-related empowerment. Res Theory Nurs Pract. 2009;23(2):107-132.

49. Barr PJ, Scholl I, Bravo P, Faber MJ, Elwyn G, McAllister M. Assessment of patient empowerment - a systematic review of measures. PLoS ONE. 2015;10(5):e0126553.

50. Li T, Wu HM, Wang F, et al. Education programmes for people with diabetic kidney disease. Cochrane Database Syst Rev. 2011;15(6): CD007374.

51. Rankinen S, Salanterä S, Heikkinen K, et al. Expectations and received knowledge by surgical patients. Int J Qual Health Care. 2007; 19(2):113-119.
Clinical Interventions in Aging

\section{Publish your work in this journal}

Clinical Interventions in Aging is an international, peer-reviewed journal focusing on evidence-based reports on the value or lack thereof of treatments intended to prevent or delay the onset of maladaptive correlates of aging in human beings. This journal is indexed on PubMed Central, MedLine,

\section{Dovepress}

CAS, Scopus and the Elsevier Bibliographic databases. The manuscript management system is completely online and includes a very quick and fair peer-review system, which is all easy to use. Visit http://www.dovepress. com/testimonials.php to read real quotes from published authors. 